\title{
African elephants and humans in conflict: the outlook for co-existence
}

\author{
Richard Hoare
}

\begin{abstract}
The future persistence of African elephants over the 80 per cent of the species's range that remains outside protected areas is increasingly uncertain in many parts of the continent. Conflict between elephants and agriculturalists is already widespread and can lead to displacement or elimination of elephants, causing a further decline in their range and numbers. 'Protectionist' conservation groups have recently attempted to play down the importance of human-elephant conflict, contending that it has been greatly exaggerated by those advocating sustainable use of wildlife. The future of elephants in ecosystems over much of the continent will depend largely upon the attitudes and activities of
\end{abstract}

\section{Introduction}

The African elephant Loxodonta africana captures the imagination of many people. Depending on one's values and one's situation, elephants may be considered as innocent and loveable, dangerous and destructive, or valuable and exploitable. In broad terms, African elephant conservation priorities have moved from concerns over habitat damage in the 1970s (Caughley, 1976; Hanks, 1979), to alarm over ivory poaching levels in the 1980s (Douglas-Hamilton, 1987; Caughley et al., 1990), and to problems involving spatial conflict with people in the 1990s (Eltringham, 1990; Kangwana, 1995). The future persistence of elephants over the 80 percent of the species's range outside protected areas is increasingly uncertaininmany parts of Africa. In the last decade, the economic value and ecological importance of elephants have become the focus of much discussion (Taylor \& Cumming, 1993; AfESG, 1997; WWF, 1997) and the extremes of the associated conservation debate have become polarized into 'protectionist' versus 'utilization' approaches to elephant management.

The issue of direct human-elephant conflict has generally escaped controversy (Dublin, 1994; Kangwana, 1995). Elephants make forays into areas of human settlement and destroy crops, raid food-stores and damage water sources, occasionally injuring or killing

Richard Hoare PO Box A222, Avondale, Harare, Zimbabwe. E-mail: rhoare@mango.zw

Received 11 December 1998. Accepted 7 July 1999 humans. The realities of survival faced by rural Africans may mean that little attention will be paid to a debate taking place on conservation philosophy in the developed world. Therefore, the IUCN African Elephant Specialist Group (AfESG) is investigating how human land use can be integrated with the needs of elephant populations in Africa's biogeographical regions. Findings from these studies will be used in attempts to benefit elephant conservation and management in the 37 African elephant range states.

Keywords African elephants, agriculture, conflict, land use.

people in the process. People retaliate by injuring, killing or using deliberate measures to displace elephants. There is increasing agreement in conservation and political circles about the need to mitigate the negative effects of this conflict on both humans and elephants.

Protectionist lobby groups have recently attempted to minimize the importance of human-elephant conflict internationally (Styles et al., 1997; Patel, 1998). They argue that human-wildlife conflict is a consequence of colonial legislation (Patel, 1998) and that the levels of conflict between humans and elephants are greatly exaggerated "by those advocating sustainable use of wildlife" and are no more serious than damage from other agricultural pest species (Styles et al., 1997). Styles et al. called for a detailed study into human-elephant conflict in order to "corroborate the arguments around human-elephant conflict or prove it to be a cynical manipulation of the truth". The Humane Society of the United States (HSUS, 1997) made a number of unsubstantiated claims against the feasibility of marketing 'problem elephants' as hunting trophies. This is a control measure that has achieved some success (Taylor, 1993) in countries where regulated elephant hunting is permitted.

\section{The African Elephant Specialist Group}

Of the 100 or so specialist groups that are part of the Species Survival Commission (SSC) of IUCN-the World Conservation Union, the African Elephant Specialist Group (AfESG) is one of the most active. The AfESG, 
which has 70 members from 37 countries comprising the elephant 'range states', has identified six issues of equal priority that need attention regarding the African elephant (AfESG, 1997; WWF, 1997). These are: (i) law enforcement, poaching and the ivory trade; (ii) habitat loss; (iii) local overpopulation of elephants; (iv) improved elephant surveys, and (v) human-elephant conflict.

Since 1997, a subgroup of the AfESG, a Taskforce on Human-Elephant Conflict, has been investigating the conservation biology of elephants that come into contact with people in each of Africa's biogeographical regions. The objective is to be able to predict how human land use can be integrated with the needs of elephant populations found in those regions. Some general principles are beginning to emerge from the work conducted to date on this very complex interaction.

\section{Present understanding of human-elephant conflict}

Initially, the AfESG compiled an inventory of sites and a bibliography of literature on human-elephant conflict in Africa, which showed that the problem is widespread. Negative interactions in some form occur almost wherever elephant range coincides with human settlement. At present, only 20 per cent of the species's range is legally protected (Said et al., 1995) but conflict occurs almost anywhere, whether or not the elephant populations involved are protected. Human-elephant conflict is a problem in both the ranges of forest elephants (mainly central and west Africa) and savannah elephants (mainly eastern and southern Africa; Thouless, 1994; Barnes, 1996; Lahm, 1996; NaughtonTreves, 1996, 1998; Newmark, 1996; Wunder, 1996; Hoare, 1999). Greater democracy and better communications have allowed the issue to become increasingly politicized locally (WWF, 1997), even if actual incidents are sporadic or of limited impact. Nevertheless, much conflict goes unreported (WWF, 1997).

Despite the widespread nature of the problem, elephants have been found to be relatively low in the list of agricultural pests when a rigorous evaluation of agricultural damage levels has been conducted in an affected area (Bell, 1984; Deodatus \& Lipiya, 1991; Simons \& Chirambo, 1991; Lahm, 1996; Wunder, 1996; Naughton-Treves, 1996, 1998). The range (typically 510 per cent) of total crop losses attributable to elephants is quite low. Widespread low levels of damage from crop pests that are not physically dangerous (e.g. primates, suids, rodents, birds and insects) are generally better tolerated than typically very localized, more obvious cases caused by large, potentially dangerous mammals such as elephants (Lahm, 1996; de Boer \& Baquete, 1998; Naughton-Treves, 1998). So far, there is little evidence to support the existence of clear relationships between levels of problems caused by elephants and either natural food limitation or local density of elephants (Barnes et al., 1995; Hoare, 1999). At present, optimal foraging theory, which predicts that animals will maximize the quality of their nutrient intake whenever possible (Begon et al., 1986), offers the most plausible explanation for the unpredictable nature of elephant raids both in savannahs (Osborn, 1998; Hoare, 1999) and forests (Lahm, 1996). In many semi-arid savannah areas, which are climatically unsuitable for subsistence agriculture even in the absence of pests, and in rain forests, where cultivated plots frequently tend to be small and poorly managed, the economic impact of elephant damage on farmers is correspondingly small.

But additional socio-economic 'opportunity costs' are borne by rural people living in proximity to elephants, stemming from the fact that problem elephants can become difficult to deter and dangerous. These 'costs' are difficult to quantify but may outweigh the direct costs of agricultural damage and be a major component of the conflict as it is perceived by local people (WWF, 1997). Examples of such opportunity costs are: restriction on people's movements; competition with elephants for water sources; the need to guard property, which may lead to loss of sleep, reduced school attendance, poor employment opportunities or greater exposure to malaria.

From current knowledge, it is improbable that human-elephant conflict can ever be completely eliminated, unless one or other of the species is removed. However, it can be ameliorated and the management objective should be to reduce it to a level that local people can tolerate. Interventions that reduce conflict significantly in one area of Africa may, however, be completely ineffective in another area. There is no universal recipe for controlling 'problem elephants', but a range of control measures, used flexibly and in combination, can be employed to mitigate the effects on people and their property (Taylor, 1993; Hoare, 1995; Barnes, 1997). Examples of these measures are: disturbance with noise, fire or weapons; killing of selected problem elephants; organizing and marketing hunts for killing problem animals; various forms of fencing; experimental repellent sprays and alarm calls; capture and translocation of elephants; compensation schemes; research effort to increase understanding of the local ecology of elephants; and, most importantly, land zonation, which reduces spatial competition between people and elephants. Interactions between human and elephant populations can in fact show surprising tolerance 
from both sides (Hoare, 1997). Relatively high densities of elephants and people can co-exist in the same ecosystem if human land uses do not involve widespread transformation of the land cover (Hoare \& du Toit, 1999) and elephants are not subjected to high levels of deliberate disturbance.

\section{Further investigation of human-elephant conflict}

The AfESG taskforce is expanding its work, moving from a descriptive to an analytical approach by research designed to provide greater understanding of humanelephant conflict processes. At least one-third of the range states are involved in a project in which research is being carried out on the topics listed below.

1. A comprehensive data collection protocol for human-elephant conflict zones is being tested in both savannahs and forests for its suitability for input into a computerized geographic information system (GIS).

2. A training package is being developed for people with no research experience to collect consistently reliable data in human-elephant conflict zones.

3. Spatial and temporal data from elephant censuses, the environment and conflict incidents are being analysed and modelled to investigate inter-relationships of causal factors in human-elephant conflict.

4. Problem elephant control policy in a sample of range states is being reviewed to identify the stakeholders and their actual or potential contributions to different elephant management objectives.

5. The relative importance of elephants in the spectrum of socially and economically important agricultural pests is being investigated.

6. Evidence is being gathered to test the hypothesis that elephant problems are often caused by a small segment of the elephant population, i.e. 'habitual' problem animals.

\section{The continental outlook}

Human-elephant conflict can be one of the precursors to further decline in the species's range. This could contribute to the erosion and eventual local extinction of elephant populations in unprotected areas in the same manner as megafaunal extinctions have occurred on other continents (Owen-Smith, 1988). Displacement and compression of elephants from unprotected areas to protected areas can have serious knock-on effects on the biodiversity of the latter (Caughley, 1976; Western, 1989; Cumming et al., 1997). Furthermore, ecosytems are impoverished by the loss of this species. Thus, the skewed density distribution of elephants frequently seen in Africa (too many in protected areas and too few in the unprotected range) is one symptom of the growing demands made by humans on the environment (Taylor \& Cumming, 1993).

Opportunities still exist (but are rapidly decreasing) to designate new protected areas that are large enough to hold elephant populations. It is clear that the future of elephants over much of the continent will depend largely upon the attitudes and activities of humans. It is also increasingly obvious that rural people facing the realities of survival will be unlikely to pay heed to a debate on conservation philosophy in the developed world. The challenge for elephant conservation, therefore, is much more complex than a simple species conservation issue. Co-operation between conservationists and agriculturalists at all levels would appear to be a prerequisite to stabilizing both the conflict interface and the wider incompatibility of humans and elephants. Land-use policy and land-use planning are fundamental, and perhaps the only, tools to facilitate compromises that may achieve long-term human-elephant co-existence.

\section{Conclusions}

The belief that the elephant's future lies only in proclaimed refugia (Parker \& Graham, 1989) may be unduly pessimistic. There is evidence that habitat availability is more important in retaining elephants than is a protection status for wildlife (Hoare, 1997; Hoare \& du Toit, 1999), particularly where the latter is poorly applied. The involvement of local people in natural resource conservation may mean that adequate protection for some of the elephant range could be achieved through a step-wise decision-making process. Simple natural resource surveys can distinguish areas where elephant conservation is possible from areas where it is not. Where elephants are to persist, their needs will have to be integrated with those of people (Sukumar, 1991; Child, 1995; Cumming, 1995). Many other wild species will benefit from these elephant conservation initiatives. There are indications that a devolved, participatory approach may be the best way of dealing with a human tolerance threshold for elephant problems (AfESG, 1997; WWF, 1997) and may increase the chances of effective interventions to combat these problems (Taylor, 1993; Hoare, 1995; Barnes, 1997).

In countries of southern Africa where national policies promote local use of wildlife resources (Lewis et al., 1990; Murphree, 1991), elephants have brought considerable financial benefit to local-level wildlife programmes (Bond, 1994). Many wildlife managers in this region are turning to a cost-benefit approach, where the benefits of elephant populations persisting outside protected areas (e.g. revenue from controlled tourism, sport hunting, or 
the sale of elephant products; conservation of other wild species) must try to outweigh the costs (e.g. effects on people, costs of control measures and habitat damage). With this wider perspective, reducing humanelephant conflict then becomes not an end in itself, but one component of accommodating these elephants.

Rhetoric on human-elephant conflict in the absence of data (HSUS, 1997; Styles et al., 1997; Patel, 1998) came in the aftermath of the Convention on International Trade in Endangered Species (CITES) meeting in 1997, when animal rights activists felt defeated by new developments to resume a tightly controlled ivory trade by three southern African countries. A political approach to the conservation of vulnerable, unprotected elephant populations, often based on opinion and complaint, is surely less viable than a scientific approach based on good data, adaptive management and carefully drawn conclusions. The AfESG is endeavouring to approach this investigation in the latter manner continent-wide, so that sound elephant management recommendations can be offered to implementing agencies in the African elephant range states.

\section{Acknowledgements}

The generous financial support of the World Wide Fund for Nature and the United States Fish and Wildlife Service for the activities of the AfESG is gratefully acknowledged. Some of the author's earlier research was supported by the Norwegian Agency for Development Co-operation (NORAD) in Zimbabwe. The IUCN Regional Office for Southern Africa provided logistical support. Russell Taylor, Jon Hutton and Holly Dublin are thanked for valuable comments made on the manuscript.

\section{References}

IUCN African Elephant Specialist Group (1997) In Review of African Elephant Conservation Priorities (ed. C. R. Thouless). Working Document of the IUCN/SSC African Elephant Specialist Group, PO Box 62440, Nairobi, Kenya.

Barnes, R.F.W., Asika, S. \& Asamoah-Boateng, B. (1995) Timber, cocoa and crop-raiding elephants: a preliminary study from southern Ghana. Pachyderm, 19, 33-38.

Barnes, R.F.W. (1996) The conflict between humans and elephants in the central African forests. Mammal Review, 26, 67-80.

Barnes, R.F.W. (1997) A proposed solution to the Kakum elephant problem. In Facing the Storm: Five Years of Research in and around Kakum National Park, Ghana. Proceedings of Kakum Conservation Area Research Colloquium, pp. 15-18. Conservation International, Washington DC.

Bell, R.H.V. (1984) The man-animal interface: an assessment of crop damage and wildlife control. In Conservation $\&$ Wildlife Management in Africa (eds R. H. V. Bell and E. McShane-Caluzi), pp. 387-416. US Peace Corps, Malawi. Begon, M., Harper, J.R. \& Townsend, C.R. (1986) Ecology: Individuals, Populations and Communities. Blackwell Scientific Publications, Oxford.

Bond, I. (1994) The importance of sport hunted African elephant to CAMPFIRE revenue in Zimbabwe. Traffic Bulletin, 14, 117-119.

Child, G. (1995) Wildlife and People: the Zimbabwean Success. Wisdom Foundation, Harare.

Caughley, G. (1976) The elephant problem-an alternative hypothesis. East African Wildlife Journal, 14, 265-283.

Caughley, G., Dublin, H.T. \& Parker, I.S.C. (1990) Projected decline of the African elephant. Biological Conservation, 54, 157-164.

Cumming, D.H.M. (1995) Are multispecies systems a viable land-use option for southern African savannas? In International Symposium on Wild and Domestic Ruminants in Extensive Land Use Systems (eds R. R. Hoffmann and H. J. Schwartz), pp. 203-234. Humbolt University, Berlin.

Cumming, D.H.M., Fenton, M.B., Rautenbach, I.L., Taylor, R.D., Cumming, G.S., Cumming, M.S. et al. (1997) Elephants, woodlands and biodiversity in southern Africa. South African Journal of Science, 93, 231-236.

de Boer, W.F. \& Baquete, D.S. (1998) Natural resource use, crop damage and attitudes of rural people in the vicinity of the Maputo Elephant Reserve, Mozambique. Environmental Conservation, 25, 208-218.

Deodatus, F.D. \& Lipiya, A.K. (1991) Vertebrate Pest Impact around Kasungu National Park, January-June 1990. FAO Field Document No.10, Department of National Parks and Wildlife, Malawi.

Douglas-Hamilton, I. (1987) Elephant population trends and their causes. Oryx, 21, 11-24.

Dublin, H.T. (1994) In the eye of the beholder: our image of the African elephant. Endangered Species Technical Bulletin, 19(1), 5-6.

Eltringham, S.K. (1990) Wildlife carrying capacities in relation to human settlement. Koedoe, 33(2), 87-97.

Hanks, J. (1979) A Struggle for Survival: The Elephant Problem. Struik Publishers, Cape Town.

Hoare, R.E. (1995) Options for the control of elephants in conflict with people. Pachyderm, 19, 54-63.

Hoare, R.E. (1997) The effects of interaction with humans on elephant populations of the Sebungwe region, Zimbabwe. DPhil Thesis, University of Zimbabwe.

Hoare, R.E. (1999). Determinants of human-elephant conflict in a land-use mosaic. Journal of Applied Ecology, 36, $689-700$.

Hoare, R.E. \& du Toit, J.T. (1999) Coexistence between people and elephants in African savannas. Conservation Biology, 13, 633-639.

HSUS (1997) CAMPFIRE: A Close Look at the Costs and Conseguences. Humane Society of the United States, 2100 L Street NW, Washington DC 20031, USA.

Kangwana, K. (1995) Human-elephant conflict: the challenge ahead. Pachyderm, 19, 11-14.

Lahm, S.A. (1996) A nationwide survey of crop-raiding by elephants and other species in Gabon. Pachyderm, 21, 69-77. 
Lewis, D.M., Kaweche, G.B. \& Mwenya, A. (1990) Wildlife conservation outside protected areas-lessons from an experiment in Zambia. Conservation Biology, 4, 171-180.

Murphree, M.W. (1991) Communities as Institutions for Resource Management. Occasional Paper Series 1991, Centre for Applied Social Sciences, University of Zimbabwe, Harare.

Naughton-Treves, L. (1996) Uneasy neighbours: wildlife and farmers around Kibale National Park, Uganda. PhD Thesis, University of Florida.

Naughton-Treves, L. (1998) Predicting patterns of crop damage by wildlife around Kibale National Park, Uganda. Conservation Biology, 12, 156-168.

Newmark, W.D. (1996) Insularization of Tanzanian parks and the local extinction of large mammals. Conservation Biology, 10, 1549-1556.

Osborn, F.V. (1998) The ecology of crop raiding elephants in Zimbabwe. PhD Thesis, University of Cambridge.

Owen-Smith, N. (1988) Megaherbivores: The Influence of Very Large Body Size on Ecology. Cambridge University Press, Cambridge.

Parker, I.S.C. \& Graham, A.D. (1989) Men, elephants and competition. Symposia of the Zoological Society of London, 61, 241-252.

Patel, H. (1998) Sustainable Utilization and African Wildife Policy: the Case of CAMPFIRE. Indigenous Environment Policy Centre, Cambridge, MA 02238, USA.

Said, M.Y., Chunge, R., Craig, G.C., Thouless, C.R., Barnes, R.F.W. \& Dublin, H.T. (1995) The African Elephant Database. IUCN/SSC Occasional Paper No. 11, IUCN, Rue Mauverney 28, CH-1196 Gland, Switzerland.

Simons, H.W. \& Chirambo, P.C. (1991) Vertebrate Pest Impact around Liwonde National Park, March-April 1990. FAO Field Document No. 11, Department of National Parks and Wildlife, Malawi.

Styles, C., Bell, J. \& Barritt, D. (1997) Human-elephant conflict: much ado about nothing? The Game Ranger, 1997, 14
Sukumar, R. (1991) The management of large mammals in relation to male strategies and conflict with people. Biological Conservation, 55, 93-102.

Taylor, R.D. (1993) Elephant management in NyamiNyami District, Zimbabwe: turning a liability into an asset. Pachyderm, 17, 19-29.

Taylor, R.D. \& Cumming, D.H.M. (1993) Elephant management in southern Africa. In Responsible Wildlife Resource Management: Balancing Biological, Economic, Cultural and Moral Considerations (eds N. D. Christoffersen and C. Lippai). European Bureau for Conservation and Development, Brussels.

Thouless, C.R. (1994) Conflict between humans and elephants in northern Kenya. Oryx, 28, 119-127.

Western, D. (1989) The ecological role of elephants in Africa. Pachyderm, 12, 42-45.

Wunder, M.B. (1996) Of elephants and men: crop destruction in two CAMPFIRE communities in the Zambezi valley, Zimbabwe. DPhil Thesis, University of Michigan, USA.

WWF (1997) In Conserving Africa's Elephants: Current Issues and Priorities for Action (eds H. T. Dublin, T. O. McShane and J. Newby). World Wide Fund for Nature International, Gland, Switzerland.

\section{Biographical sketch}

Dr Richard Hoare is an independent consultant acting as chairman of a voluntary Taskforce on Human-Elephant Conflict in the IUCN/SSC African Elephant Specialist Group. His recent work has involved researching aspects of human-elephant interaction at the population level in African ecosystems and has been published in Conservation Biology and the Journal of Applied Ecology. 